\title{
A educação em saúde na Estratégia Saúde da Família sob a perspectiva do enfermeiro: uma revisão de literatura
}

Marcelle Aparecida de Barros Junqueira1 , Fabiana Carla da Silva Santos²

\begin{abstract}
Resumo
De acordo com as diretrizes da Política de Promoção da Saúde, a educação em saúde é uma das estratégias utilizadas para efetivar uma aproximação entre os serviços de saúde e a comunidade. Este estudo objetiva descrever a produção científica sobre educação em saúde na Estratégia Saúde da Família, na perspectiva do enfermeiro. Foi utilizada uma busca online, por meio da base de dados LILACS; com os descritores: Programa Saúde da Família, educação em saúde, enfermeiro. Os resultados mostraram 15 trabalhos, os quais atendiam aos critérios de inclusão e delinearam quatro eixos temáticos: "Educação em Saúde realizada a partir do modelo tradicional"; "Dificuldades do profissional enfermeiro em atividades educativas"; "Práticas educativas voltadas a grupos de pacientes com patologias específicas"; "Necessidade de formação adequada do enfermeiro para atender as novas demandas de educação em saúde". Percebe-se que o modelo de educação em saúde praticado pelos enfermeiros ainda se mantêm no modelo tradicional e hegemônico, sendo realizada somente como transferência de conhecimentos. É necessária uma mudança no currículo das universidades para a formação consistente em educação em saúde, além da necessidade da educação permanente àqueles profissionais que já atuam na atenção primária, a fim de que se possa compartilhar e construir conhecimentos em saúde de maneira realmente emancipatória, efetiva e transformadora.
\end{abstract}

\section{Palavras-chave}

Educação em Saúde. Enfermeiro. Programa Saúde da Família.

1. Doutora em Ciências pela Universidade de São Paulo, professora no curso de Enfermagem da Faculdade de Medicina da Universidade Federal de Uberlândia. E-mail: marcellebarros@famed.ufu.br.

2. Graduada em Enfermagem pela Universidade Federal de Uberlândia. E-mail: fabi_nurse@yahoo.com.br. 


\title{
The health education in the Family Health Strategy from the perspective of the nurse: a literature review
}

\author{
Marcelle Aparecida de Barros Junqueira*, Fabiana Carla da Silva Santos**
}

\begin{abstract}
According to the guidelines of Health Promotion, health education is seen as one of the strategies used to get a closer relationship between health services and the community. This study aims to describe what the scientific literature has revealed about health education in family health strategy: in the nurses ' perspective, for this literature review, we used an online search through the LILACS database. The keywords used were: the Family Health Program, health education, nurse. The results showed 15 studies which met the inclusion criteria and outlined four thematic areas: "Health Education, held from the traditional model"; "The nurse difficulties in educational activities"; "Educational practices aimed at groups of patients with specific pathologies"; "The need of better formation courses for nurses to meet the new demands of health education". It is perceived that the model of education in health practiced for the nurses still is remained in the traditional and hegemonic model, being only carried through as transference of knowledge. A change in the resume of the universities for the consistent formation in education in health is necessary, beyond the necessity of the permanent education to those professionals who already act in the primary attention, so that if she can share and construct knowledge in health in really emancipatory way, effective and transforming.
\end{abstract}

\section{Keywords}

Education in Sealth. Nurse. Program Health of the Family.

\footnotetext{
* Doctor in Sciences at the University of São Paulo, professor in the Nursing course at the Medicine Faculty at the Federal University of Uberlândia. E-mail: marcellebarros@famed.ufu.br.

** Nursing graduated at the Federal University of Uberlândia. E-mail: fabi_nurse@yahoo.com.br.
} 


\section{Introdução}

A Estratégia de Saúde da Família é um projeto dinamizador do Sistema Único de Saúde (SUS), condicionada pela evolução histórica e pela organização do sistema de saúde no Brasil. A velocidade de expansão da Saúde da Família comprova a adesão de gestores estaduais e municipais aos seus princípios. Iniciado em 1994, apresentou um crescimento expressivo nos últimos anos. A consolidação dessa estratégia precisa, entretanto, ser sustentada por um processo que permita a real substituição da rede básica de serviços tradicionais no âmbito dos municípios e pela capacidade de produção de resultados positivos nos indicadores de saúde e de qualidade de vida da população assistida (BRASIL, 2011).

A expansão e a qualificação da atenção básica, organizadas pela Estratégia Saúde da Família, compõem parte do conjunto de prioridades políticas apresentadas pelo Ministério da Saúde e aprovadas pelo Conselho Nacional de Saúde. Esta concepção supera a antiga proposição de caráter exclusivamente centrado na doença, desenvolvendo-se por meio de práticas gerenciais e sanitárias, democráticas e participativas, sob a forma de trabalho em equipes, dirigidas às populações de territórios delimitados, pelos quais assumem responsabilidade (BRASIL, 2011).

\section{Saúde e Educação: intersecção entre dois campos}

De acordo com Freire (1987), educação é comunicação, é diálogo, na medida em que não é transferência de saber, mas um encontro de sujeitos interlocutores que buscam a significação dos significados.

Educar não significa simplesmente transmitir/adquirir conhecimentos. Existe, no processo educativo, um arcabouço de representações de sociedade e de homem que se quer formar. Por meio da educação, as novas gerações adquirem os valores culturais e reproduzem ou transformam os códigos sociais de cada sociedade (PEREIRA, 2003). A educação não é sinônimo de transferência de conhecimento pela simples razão de que não existe um saber feito e acabado, suscetível de ser captado e compreendido pelo educador e, em seguida, depositado nos educando. Segundo Freire (1987), a educação, a partir da transmissão de informações, consiste em uma educação "bancária", pois

quanto mais se exercitem os educando no arquivamento dos depósitos que lhes são feitos, tanto menos desenvolverão em si a consciência crítica de que resultaria a sua inserção no mundo, como transformadores dele, como sujeitos (BACKES et al, 2008).

De acordo com Backes e colaboradores (2008) e Santos e Penna (2009), é possível compreender que a educação em saúde está intimamente relacionada com as ações cuidadoras. Isso nos remete à dupla identidade dos profissionais de saúde - a de educador e a de trabalhador de saúde. Essa duplicidade mostra que a educação ocupa lugar central no trabalho em saúde e, muitas vezes, é o que o torna viável. Não é possível pensar a saúde sem, simultaneamente, pensar a educação e as relações existentes entre ambas.

E é exatamente nessa perspectiva, que o Ministério da Saúde preconiza a prática da educação em saúde, pois essa linha de pensamento converge para a interssetorialidade e interdisciplinaridade e é significativamente mais rica culturalmente e mais produtiva quando o conhecimento é considerado. Além disso, a articulação entre educação e saúde, sob a ótica da relação interpessoal, do cuidado e do 
respeito, constitui-se como uma das mais ricas fontes de interdisciplinaridade (FERNANDES; BACKES, 2010).

\section{Educação em saúde}

A educação em saúde é vista, hoje, como uma das estratégias utilizadas na atenção primária para efetivar uma aproximação entre os serviços de saúde e a comunidade, entre o educador e o educando, em um processo de ensino-aprendizagem. A educação em saúde é o processo educativo complexo e de construção permanente, no qual acontece a troca de conhecimento, em geral de saúde, de costume e cultura, com a finalidade debater e promover a tomada de decisão de uma população sobre as práticas de saúde (FERNANDES; BACKES, 2010).

É, ainda, uma prática de competência importante e inerente ao trabalho do enfermeiro, que deve ser continuamente desenvolvida e avaliada, visto que a educação em saúde, avaliada pela ótica do processo político pedagógico requer o desenvolvimento de um pensar crítico e reflexivo, permitindo desvelar a realidade e propor ações transformadoras que levem o indivíduo a sua autonomia e emancipação enquanto sujeito histórico e social, capaz de propor e opinar nas decisões de saúde para cuidar de si, de sua família e da coletividade (MACHADO et al., 2007).

É também um conjunto de práticas que contribui para aumentar a autonomia das pessoas no seu cuidado e no debate com os profissionais e gestores, para alcançar uma atenção de saúde de acordo com as necessidades do local. A educação em saúde potencializa o exercício da participação popular e do controle social sobre as políticas e os serviços de saúde, no sentido de que respondam às necessidades da população (BRASIL, 2009).

A educação em saúde deve ser vista como prática social e um processo capaz de desenvolver a reflexão e a consciência crítica das pessoas sobre as causas de seus problemas de saúde, enfatizando o desencadeamento de um processo baseado no diálogo, de modo que se passe a trabalhar com pessoas e não, para as pessoas (MACHADO et al., 2007). Ressaltando, ainda, a importância do tipo de diálogo e de comunicação que o profissional estabelece com a comunidade para efetivar a educação em saúde, pode ser uma oportunidade para ajudar o outro a ampliar sua capacidade para enfrentar a realidade em que vive e descobrir soluções práticas para resolver seus problemas e conflitos e a se ajustar ao que não pode ser mudado, caminhando para a independência e autonomia (STEFANELLLI; CARVALHO, 2005).

Portanto o profissional que vai trabalhar com famílias deve conhecer valores, crenças e procedimentos. Para se relacionar com o outro, este profissional deve primeiro conhecer os próprios pensamentos e sentimentos e aceitar-se como ser humano para depois interagir de forma efetiva (STEFANELLLI; CARVALHO, 2005). A educação em saúde é a estratégia adotada pelo SUS para a promoção da saúde na comunidade à qual contribui estrategicamente para a identificação e planejamento das ações no nível primário de atenção à saúde e incentiva a procura de soluções coletivas dos problemas, promovendo debates, tomadas de decisões e práticas de saúde com a comunidade.

Torna-se importante conhecer a relevância dessas práticas para os profissionais enfermeiros que trabalham na Estratégia Saúde da Família. Visto que para realização do processo educativo em saúde é necessário que o profissional se utilize de habilidades e conceitos sobre cultura, estilos de vida, política, sociedade e religião (MACHADO et al., 2007). É importante ressaltar que a perspectiva na qual a educação em saúde é realizada pode ser um entrave para o entendimento acerca do que o profissional irá ensinar ou, como afirma Boebs e colaboradores (2007), pode ser um processo no qual se 
inclui decisões, negociações, rituais e rotinas.

O envolvimento do enfermeiro nas ações que visam à educação em saúde, desenvolvidas junto à comunidade, garante uma crescente integralidade e produção de equidade, o que é importante para as atividades desenvolvidas cotidianamente nos serviços de saúde.

Muitos profissionais acreditam que a "palestra" ainda é a metodologia que melhor simboliza a educação em saúde (BOEBS et al, 2007). No entanto, sabemos que, de maneira verticalizada, com temas prontos e sem interação com o indivíduo, não acontece educação em saúde, apenas repasse de informações, o que é insuficiente para produzir mudança de comportamento.

Diante do atual contexto, percebe-se que a atuação da enfermagem na atenção primária é extremamente importante, porém, na prática, o que se percebe é que os profissionais não têm dado tal relevância às atividades relacionadas à educação em saúde na Estratégia Saúde da Família. Isto acontece, com certeza, por vários fatores, no entanto o que direciona este trabalho vem dos seguintes questionamentos: O que os estudos brasileiros têm mostrado quanto às percepções, conceitos e ações dos enfermeiros sobre a educação em saúde na Estratégia Saúde da Família? Quais são os fatores que mais emergem desses estudos?

Portanto, o objetivo desse estudo foi descrever a produção científica acerca da educação em saúde na Estratégia Saúde da Família na perspectiva do enfermeiro.
Método

As etapas da revisão foram preconizadas e padronizadas pelo referencial metodológico de Galvão, Sawada e Trevisan (2004). Para sua operacionalização, foram seguidas as seguintes etapas:

1. Estabelecimento do problema de revisão: o problema da revisão foi o conteúdo da produção científica acerca da educação em saúde na Estratégia Saúde da Família na perspectiva do enfermeiro.

2. Seleção da amostra de publicações ${ }^{3}$ : para essa revisão de literatura foi utilizada uma busca online, por meio da base de dados LILACS $^{4}$, realizada em novembro de 2011, e utilizados os descritores: Programa Saúde da Família, educação em saúde, enfermeiro.

3. A seleção dos estudos: após a leitura inicial dos títulos e resumos, para avaliar a coerência dos estudos a serem pesquisados, e obedecendo-se os critérios relatados, o total de referências para análise se perfez em 15 trabalhos na íntegra.

\section{Resultados e Discussão}

\section{Caracterização dos estudos}

Na Tabela 1, foram distribuídos os 15 trabalhos de acordo com o ano, título e local de publicação.

3. Como critérios de inclusão foram selecionados estudos que: estivessem disponibilizados na íntegra e tivessem relação com o objetivo proposto. Como critérios de exclusão foram adotados: artigos que não estivessem em português, inglês ou espanhol e que não fossem diretamente relacionados com o Programa Saúde da Família.

4. Foram encontradas 31 referências na base de dados LILACS e selecionadas 15 delas para análise. 
Tabela 1 - Relação de artigos publicados sobre educação em saúde na Estratégia Saúde da Família, na perspectiva do enfermeiro $(\mathrm{N}=15)$.

\begin{tabular}{|c|c|c|}
\hline Ano & Título & Local \\
\hline 2002 & Educação de pacientes com asma: atuação do enfermeiro & Jornal de Pneumologia \\
\hline 2003 & $\begin{array}{l}\text { Reflexão sobre a importância da temática saúde da família } \\
\text { no ensino da graduação em enfermagem }\end{array}$ & $\begin{array}{l}\text { Revista Brasileira de } \\
\text { Enfermagem }\end{array}$ \\
\hline 2006 & $\begin{array}{l}\text { Grupo de Orientação de Cuidados aos Familiares de } \\
\text { Pacientes Dependentes }\end{array}$ & $\begin{array}{l}\text { Revista Brasileira de } \\
\text { Enfermagem }\end{array}$ \\
\hline 2006 & $\begin{array}{l}\text { Enfermeiro \& grupos em PSF: possibilidade para } \\
\text { participação social }\end{array}$ & Cogitare Enfermagem \\
\hline 2006 & $\begin{array}{l}\text { Conhecimento de enfermeiros sobre sua atuação em } \\
\text { saneamento básico no Programa de Saúde da Família (PSF) } \\
\text { em Guarapuava - PR }\end{array}$ & $\begin{array}{l}\text { Espaço para a saúde } \\
\text { (online) }\end{array}$ \\
\hline 2007 & $\begin{array}{l}\text { Trabalhar com famílias no Programa de Saúde da Família: a } \\
\text { prática do enfermeiro em Maringá-Paraná }\end{array}$ & $\begin{array}{l}\text { Revista da Escola de } \\
\text { Enfermagem da USP }\end{array}$ \\
\hline 2007 & $\begin{array}{l}\text { Práticas de saúde em Enfermagem e Comunicação: um } \\
\text { estudo de revisão da literatura }\end{array}$ & Ciência e Saúde Coletiva \\
\hline 2008 & $\begin{array}{l}\text { A prática gerencial do enfermeiro no PSF na perspectiva da } \\
\text { sua ação pedagógica educativa: uma breve reflexão }\end{array}$ & Ciência e Saúde Coletiva \\
\hline 2008 & $\begin{array}{l}\text { O discurso do enfermeiro sobre a prática educativa no } \\
\text { Programa Saúde da Família em Juiz de Fora, Minas Gerais, } \\
\text { Brasil }\end{array}$ & Revista de APS \\
\hline 2008 & $\begin{array}{l}\text { Educação para saúde como estratégia de intervenção de } \\
\text { enfermagem junto às pessoas portadoras de diabetes }\end{array}$ & $\begin{array}{l}\text { Revista Eletrônica de } \\
\text { Enfermagem }\end{array}$ \\
\hline 2009 & $\begin{array}{l}\text { Enfermeiros coordenadores de equipe do Programa Saúde } \\
\text { da Família: perfil profissional }\end{array}$ & $\begin{array}{l}\text { Revista da Escola de } \\
\text { Enfermagem da UERJ }\end{array}$ \\
\hline 2010 & $\begin{array}{l}\text { Hermenêutica e o cuidado de saúde na hipertensão arterial } \\
\text { realizada por enfermeiros na Estratégia Saúde da Família }\end{array}$ & $\begin{array}{l}\text { Escola Anna Nery. Revista } \\
\text { de Enfermagem }\end{array}$ \\
\hline 2010 & $\begin{array}{l}\text { A Educação em Saúde na Estratégia Saúde da Família: uma } \\
\text { revisão bibliográfica das publicações científicas no Brasil }\end{array}$ & $\begin{array}{l}\text { Journal Health Science } \\
\text { Institute }\end{array}$ \\
\hline 2010 & $\begin{array}{l}\text { Educação permanente no Programa Saúde da Família: um } \\
\text { estudo qualitativo }\end{array}$ & $\begin{array}{l}\text { Investigación y } \\
\text { educación en enfermería }\end{array}$ \\
\hline 2010 & $\begin{array}{l}\text { Conhecimento, uso e escolha de métodos contraceptivos } \\
\text { por um grupo de mulheres de uma Unidade Básica de } \\
\text { Saúde em Teresópolis/RJ }\end{array}$ & Cogitare Enfermagem \\
\hline
\end{tabular}

Fonte: Produzida pelas autoras. 
Na tabela acima, percebe-se que a maioria dos estudos foi publicada em 2010. Destacando-se, também, um aumento do número de publicações a partir do ano de 2006.

\section{Análise descritiva dos estudos}

A análise descritiva dos artigos encontrados possibilitou o entendimento da educação em saúde, na Estratégia Saúde da Família, a partir da perspectiva do enfermeiro, por meio da convergência de quatro grandes temas de discussão: "Educação em Saúde realizada a partir do modelo tradicional"; "Dificuldades do profissional enfermeiro em atividades educativas"; "Prática educativa voltada a grupos de pacientes com patologias especificas"; "Necessidade de formação adequada do enfermeiro para atender as novas demandas de educação em saúde".

\section{Educação em Saúde realizada a partir do modelo tradicional}

As principais atividades encontradas, desenvolvidas de educação em saúde na Estratégia Saúde da Família, foram orientações em grupos (grupos de gestante, diabéticos, hipertensos), "as palestrinhas" e orientações sobre higiene, hábitos saudáveis, mecanismos das doenças, ou seja, ainda se mantêm uma forma de fazer educação em saúde verticalizada, conservando metodologias tradicionais e o modelo hegemônico, no qual o profissional de saúde ainda cumpre o papel de "detentor do saber". A população, por sua vez, é "vazia de conhecimentos", sendo este um senso comum entre profissionais da área, o que dificulta a formação de vínculos efetivos com a comunidade (ARAUJO et al., 2010); (JESUS et al., 2008); (CARRIJO; PONTES; BARBOSA et al., 2003); (OLIVEIRA; MARCON, 2007).
A atuação tradicional da saúde conduz a comunidade a uma compreensão fragmentada da sua realidade familiar e comunitária, gerando dependentes sociais. Dessa forma, tem- se enfrentado problemas com o desenvolvimento de um novo modelo assistencial (CARRIJO; PONTES; BARBOSA, 2003). O modelo hegemônico, o qual focaliza a doença, e a intervenção curativa, fundamentada no referencial "biologicista" do processo saúde-doença, preconiza a prevenção das doenças a partir de mudanças de comportamentos individuais (SILVA et al, 2006).

Segundo Oliveira e Marcon (2007), a concepção de educação em saúde dos enfermeiros ainda é tradicionalista, já que estipula que o repasse do saber acontece verticalmente, junto a um indivíduo passivo que deve modificar seu comportamento de acordo com o que lhe é recomendado.

O grande desafio para os trabalhadores do Programa Saúde da Família, em especial os da enfermagem, é a necessidade de rever sua prática diante de novos paradigmas, sendo indispensável repensar os processos de trabalho, bem como adotar metodologias, instrumentos e conhecimentos diferentes dos atualmente instituídos (VILLAS BÔAS; ARAÚJO; TIMÓTEO, 2008).

Os estudos caracterizam o cuidado da saúde da família como prática tradicional de abordagem individual, pois consideram qualquer intervenção da equipe como familiar e faz com que o termo família perca a sua especificidade, dificultando o alcance da integralidade e do cuidado.

Em relação ao PSF, vale ressaltar que é necessário reconsiderar metas e promover reajustes na prática acerca do trabalho com famílias, ponderando que os princípios e diretrizes do programa, por si só, são incapazes de responder ao propósito de inversão do modelo assistencial tradicional, exigindo ações muito mais abrangentes do que a 
capacidade de intervenção das equipes de saúde da família (OLIVEIRA; MARCON, 2007).

Estudos mostraram que o princípio da integralidade do cuidado, que é valorizado pela Estratégia de Saúde da Família, não consegue se efetivar nas Unidades. O trabalho das equipes se mostra inautêntico com a proposta desta estratégia, que preconiza ações educativas coletivas de saúde realizadas em equipe. Sabe-se que, quando não são consideradas as complexidades do usuário e sua experiência diante do desequilíbrio da sua saúde, há dificuldades em se obter resultados positivos com a decisão terapêutica. Esse modo de cuidar centrado na doença, e não na pessoa humana, sobressai no discurso dos enfermeiros que atuam nessas equipes (ARAÚJO; PAZ; MOREIRA, 2010).

$O$ modelo tradicional e hegemônico de se realizar a educação em saúde deve ser rediscutido, ou seja, um novo modelo deve ser adotado, para que, assim, se valorize uma abordagem de educação em saúde na qual a emancipação social ocorra inerente ao processo de melhoria da qualidade de vida, por meio da promoção da saúde individual e coletiva. Esta nova abordagem tem como marco inicial o indivíduo inserido em seu contexto social e não a sua doença, priorizando não somente a compensação dos sintomas da enfermidade, mas, principalmente, a promoção em saúde, além de outros aspectos da vida.

\section{Dificuldades do profissional enfermeiro em atividades educativas}

É importante ressaltar que são vários os entraves e as barreiras que o profissional enfermeiro encontra para desenvolver suas atividades na Estratégia Saúde da Família: a organização por parte dos gestores, a formação profissional do enfermeiro, o despreparo técnico científico, a falta de investimentos na capacitação dos profissionais, a falta de recursos para desenvolver as atividades propostas por essa estratégia, dificuldade de trabalho em equipe, e, ainda, a falta de conhecimento da população em relação às responsabilidades dos profissionais da equipe de saúde, o que dificulta o desenvolvimento das atividades na unidade de saúde e também em outros espaços na comunidade.

Estudos como os de Cervo e Ramos (2006); Silva e colaboradores (2006), Araújo e colaboradores (2010); Jesus e colaboradores (2008) refletem uma grande insatisfação dos enfermeiros quanto ao sistema de gestão. Os profissionais referem que se sentem desassistidos para realizarem o seu trabalho com a comunidade local, pois há uma sobrecarga de responsabilidades administrativas e de coordenação, o que inviabiliza o desenvolvimento de outras atividades, como as educativas, consideradas por eles como importantes. Em consequência disto, continuam mantendo condutas que privilegiam as ações curativas e o trabalho individual, atendendo a demandas, centrando-se em rotinas, e conservando um tipo de assistência centrada na doença e não no indivíduo.

O trabalho das equipes de saúde, teoricamente, permitiria uma abordagem multidisciplinar com vista à resolução dos problemas e às necessidades de saúde apresentados pelos usuários, garantindo, assim, o cuidado integral ao indivíduo, mas isto não ocorre na visão dos enfermeiros.

Encontrar alternativas cotidianas para que as atividades administrativas caminhem integradas às atividades assistenciais, na perspectiva da integralidade, da mudança na formação e da construção do gerenciamento do cuidado, voltado para uma prática educativa transformadora, constitui um grande desafio (VILLAS BÔAS; ARAÚJO; TIMÓTEO, 2008). Um estudo realizado na cidade de Juiz de Fora - MG, sobre a concepção do enfermeiro acerca da educação em saúde, revelou que 
a maioria dos entrevistados mencionou falta de investimentos financeiros em material, em recursos humanos e na estrutura física da Unidade de Saúde, grande demanda ao serviço e elevada atividade burocrática no Programa Saúde da Família, como dificuldades para realizar práticas de educação em saúde (SILVA et al., 2006).

Segundo Araújo e colaboradores (2010), o trabalho fragmentado e individual não favorece ao enfermeiro condições para modificar sua atuação, que se encontra focada na organização das ações individuais, repetindo um modelo biomédico que, ao invés de aproximá-lo dos princípios do trabalho em equipe - que considera os problemas e as necessidades de saúde dos usuários na coletividade - afasta-o da população e do próprio movimento de integração entre as ações que a Unidade de Saúde da Família (USF) é capaz de oferecer.

Em estudo sobre hipertensão arterial, realizado na cidade Pau dos Ferros-RN, revelou que são poucos os recursos disponibilizados para a execução do trabalho de educação em saúde nas USF, dado esse marcante para o grupo de entrevistados (enfermeiros), uma vez que essa situação limita a difusão das informações sobre a saúde e o cuidado. Não se trata apenas da restrição de recursos financeiros para apoiar tais atividades e, sim, do apoio logístico como material educativo para distribuição nas comunidades, de dotar as unidades saúde da família de infraestrutura física adequada que favoreça o acolhimento e o trabalho coletivo de reestruturação do modelo assistencial (ARAÚJO; PAZ; MOREIRA, 2010).

O profissional enfermeiro, como mostram os estudos, dá grande importância aos grupos comunitários como sendo uma oportunidade para desenvolver educação em saúde. Contudo, um estudo realizado por Silva e colaboradores (2006), em uma USF na cidade de CuiabáMT, mostra que os grupos informados pelos enfermeiros podem ser classificados como terapêuticos, de convivência ou focais e não grupos comunitários, que são os que mais se aproximam da estratégia do PSF. Mesmo assim, a realização dos grupos é baixa, de acordo com o estudo. Isto porque são vários os obstáculos encontrados para a realização de atividades grupais: falta de domínio dessa tecnologia pelos profissionais, que se propõem a coordenar grupos; locais impróprios; pouca participação dos membros do grupo; exigência formal para a sua realização; a centralização no coordenador; conteúdos que despertam pouco interesse; predeterminação dos temas; ausência de informações técnicas sobre operacionalização de grupos nos manuais do Ministério da Saúde (SILVA et al., 2006).

A realização de grupos não se constitui uma tarefa fácil, diante da gama de atividades que os profissionais de saúde do Programa Saúde da Família têm que desenvolver. Somase a isso a concepção da população e dos gestores sobre atenção à saúde, centrada na ação do médico, com predominância no consumo de exames e de medicamentos, dificultando a participação dos profissionais em atividades educativas (SILVA et al, 2006).

Para que a estratégia do Programa Saúde da Família consolide-se como um novo modelo assistencial, é necessário romper com as práticas reducionistas e fragmentadas, as quais mantêm o enfoque na doença e no tratamento.

\section{Práticas educativas voltadas a grupos de pacientes com patologias específicas}

O estudo realizado por Silva e colaboradores (2006) concluiu que existe uma predominância da realização de grupos, conforme os recortes programáticos vigentes na prática da saúde pública tradicional: hipertensos, diabéticos, idosos e gestantes. Situações que fogem à prática tradicional da saúde pública - como a atenção aos adolescentes e aos portadores de sofrimento 
mental - ainda não se consolidaram como espaço de atuação do enfermeiro no trabalho com grupos. Considerando essas informações, à luz dos objetivos do Programa Saúde da Família, observa-se que, apesar do aumento de cobertura populacional decorrente da implantação dessa estratégia, persistem obstáculos para o alcance de alguns princípios do Sistema Único de Saúde (SUS), como a integralidade, a participação popular, o controle social e outros.

A imposição de condutas centradas nos recortes programáticos, como no controle de hipertensos e diabéticos, tornou-se mais evidente com a implantação do Programa Saúde da Família. Essas ações passaram a ser consideradas pelos profissionais como de promoção da saúde. Entretanto, são realizadas na perspectiva de orientações para a autonomia do cuidado, não abordando os condicionantes e/ou determinantes do processo saúde-doença. Assim, o processo encaminha-se no sentido da manutenção de uma dada realidade, sem problematizá-la (SILVA et al., 2006).

Um estudo de Costa e colaboradores (2010) destacou que trabalhadores relataram a excessiva repetição de atividades de educação sobre temas como Doenças Sexualmente Transmissíveis (DST's) e Síndrome da Imunodeficiência Adquirida (AIDS). Além disso, expressam a necessidade de explorar outras temáticas atreladas a acidentes domésticos do cotidiano dos moradores das comunidades.

As atividades individuais e coletivas, desenvolvidas nas unidades, são relacionadas à orientação para mudanças no estilo de vida, esclarecimentos sobre como tomar a medicação corretamente (incluindo a transcrição da receita mensal), importância da incorporação de uma alimentação saudável e encaminhamentos aos outros profissionais que dão apoio à Equipe de Saúde da Família (ESF) local. Suas atividades não ocorrem de forma sistemática e dependem diretamente do interesse do usuário em participar das ações coletivas de educação em saúde ou ida à USF para consultas individuais com os enfermeiros (ARAÚJO; PAZ; MOREIRA, 2010).

\section{Necessidade de formação adequada do enfermeiro para atender às novas demandas de educação em saúde}

De acordo com Rodrigues e Santos (2010), em uma análise dos estudos bibliográficos produzidos sobre o tema Educação em Saúde, permitiu-se concluir que o principal entrave para o desenvolvimento do modelo dialógico/problematizador (ao invés do modelo tradicional/biologicista) é a falta de formação dos profissionais da equipe de enfermagem voltada para uma mudança de paradigma profissional para a prática da Educação em Saúde. Em estudo realizado por Carrijo, Pontes e Barbosa (2003) conclui-se que se deve construir a prática de enfermagem dentro do PSF e capacitar os enfermeiros para atuarem segundo essa prática. A tarefa educativa deve buscar ensinar os enfermeiros a "aprender a aprender". Ou seja, construir profissionais que sejam capazes não só de executar técnicas de trabalho, mas que sejam críticos de sua prática e interpretem e construam as mudanças que forem necessárias, segundo a realidade em que vivem.

Ao coordenar a equipe do Programa Saúde da Família, o enfermeiro tem a atribuição de incentivar o trabalho coletivo para efetivar o trabalho em equipe e atingir a produtividade máxima e um nível de qualidade de serviço em saúde capaz de superar as expectativas dos usuários. Esse profissional tem como desafio ser agente de mudança e transformação no PSF, coordenando a equipe e fazendo dela instrumento de ações assertivas e resolutivas. Porém, nem sempre é considerado o conhecimento, a formação e as habilidades necessárias para exercer essa função. Estudos realizados no Brasil nos últimos anos discutem essa questão, sendo que alguns são centrados no 
perfil dosenfermeiroscoordenadores, mostrando a limitação de muitos profissionais no que diz respeito à formação especifica para assumir essa tarefa, além dos desafios enfrentados por esse profissional, uma vez que se trata de um papel ainda em construção (ROCHA et al., 2009).

Os princípios que regem a formação do enfermeiro devem passar por questões contextuais, eliminando-se a dicotomia entre o pensar e o fazer. O mercado de trabalho tem exigido uma mudança na formação e no exercício profissional, fato que vem demandando, por parte das faculdades, mudanças em seus currículos e em suas práticas pedagógicas. Diante da problemática que envolve a formação do enfermeiro, a inadequação dos currículos gera o despreparo dos profissionais, sendo detectadas as dificuldades com relação ao trabalho com a comunidade, trabalho em equipe, compreensão das diretrizes dos programas direcionadas à saúde da comunidade (CARRIJO; PONTES; BARBOSA, 2003). Um estudo realizado por Carrijo, Pontes e Barbosa (2003), na cidade de Goiânia-GO, com enfermeiros do Programa Saúde da Família, revelou que uma das importantes interseções entre saúde e educação é a adequação dos "produtos" acadêmicos - graduandos, conhecimento produzido e serviços prestados - às necessidades sociais, situação que está longe da ideal. Os órgãos de formação superior reafirmam a tradição de autonomia. Se, por um lado, essa autonomia livrou as universidades de imposições conjunturais, por outro, propiciou o afastamento de seu constituinte principal, que é a sociedade, na qual prevalecem vários problemas de resolução complexa. Em estudo realizado na cidade de Guarapuava-PR, sobre a atuação do enfermeiro em saneamento básico, revelou que grande parte dos entrevistados atribuiu suas dificuldades à formação profissional, apontando que a graduação é incipiente e que a falta de subsídios para atuar em saneamento básico é uma falha das universidades, que preparam mal os alunos, e das instituições que contratam o profissional (CERVO; RAMOS, 2006).

Os processos educativos servem como um instrumento de trabalho, de forma que os enfermeiros podem ser ao mesmo tempo aprendizes (objetos) e produtores (sujeitos) desses processos no trabalho. É importante ressaltar que a educação permanente visa à transformação dos trabalhadores em sujeitos a partir da modificação de valores e conceitos, colocando-os no centro do processo de ensino/ aprendizagem. Dessa forma, por meio da ação e reflexão do trabalhador sobre o trabalho que realiza, o seu conteúdo pode ser transformado e desdobrado em substancialidade, mediado pelas relações sociais cada vez mais complexas e articuladas por interesses diversos. É a partir do interesse que se reproduzem e se recriam novos conceitos a serem operados ou materializados (COSTA et al., 2010).

Com a intenção de melhorar a atuação dos profissionais que trabalham com famílias, o Ministério da Saúde começou a apoiar, financeiramente, cursos de especialização e residência em Saúde da Família, com o intuito de que os profissionais inseridos nos PSF se qualifiquem, e se tornem aptos para atuar junto à comunidade com uma visão humanística, valorizando o indivíduo. Porém, para se produzir mudanças efetivas na atuação do enfermeiro e diminuir a distância entre os currículos das universidades e as reais necessidades sociais, ainda faz-se necessário induzir mudanças nos currículos de graduação, na qual a transferência do conhecimento ainda é feita de maneira fragmentada, centrada no professor, com valorização de habilidades técnicas e modelos de avaliação que privilegiam a memorização e a reprodução de conhecimentos. 


\section{Considerações Finais}

De acordo com a análise da produção científica sobre a educação em saúde na Estratégia Saúde da Família na perspectiva do enfermeiro, foi possível observar um aumento da produção científica sobre este tema nos últimos anos, sendo mais exato a partir do ano de 2006. Isto se deve ao fato de os profissionais estarem percebendo melhor a importância desta atividade, tendo em vista que, para se alcançar uma prática de saúde transformadora e, a partir daí, se conseguir uma mudança de comportamento do indivíduo e da comunidade, é preciso buscar uma educação em saúde diferente da praticada atualmente nas Unidades da Estratégia Saúde da Família como mostraram os estudos analisados. A análise dos trabalhos científicos revelou que o enfermeiro ainda trabalha mantendo uma atuação tradicional, baseada no modelo hegemônico, centrado na doença e não no indivíduo. Os profissionais continuam trabalhando de forma sistemática, não levando em contaascrenças, a cultura eosvalores do outro, criando, assim, uma barreira entre o profissional e o indivíduo que dificulta a integralidade do cuidado que é o desejável na Estratégia Saúde da Família de acordo com as diretrizes do SUS.

Mostrou, também, que, mesmo quando os profissionais acreditam estar fazendo educação em saúde, na verdade não fazem mais do que um repasse de informação. Ou seja, não oferece oportunidade para que o usuário seja autônomo, pois essa prática - na qual se diz o que tem que ser feito, mas não mostra o porquê tem que ser feito assim - só cria dependentes sociais do sistema de saúde.

Um ponto importante, de acordo com a amostra dos trabalhos, foi sobre as dificuldades enfrentadas pelo profissional enfermeiro para conciliar suas atividades educacionais e administrativas. Os entraves são vários, desde o acúmulo de funções (como as burocráticas e administrativas), passando pelo cumprimento de metas estabelecidas pelos órgãos gestores, até a falta de espaço adequado, que inviabilizam, dessa forma, a práticas relacionadas com a prevenção e a promoção da saúde como a educação em saúde.

Foi ressaltada até mesmo a crença do usuário de que se deve procurar a unidade de saúde somente por medo de alguma doença ou sintoma. Isto se torna uma barreira para a prática educativa, pois não existe um interesse, um envolvimento do usuário com a equipe, o que torna difícil desenvolver, de forma efetiva, as atividades propostas para a promoção da saúde.

Ainda de acordo com os estudos analisados, foi possível evidenciar que a forma de atuação do enfermeiro na Estratégia Saúde da Família vem mantendo, ainda, uma conduta biologicista, conservando o modelo tradicional e hegemônico, no qual o repasse de informações ainda é feito de forma verticalizada para um usuário passivo. Esta conduta é, principalmente, um reflexo da formação profissional que estes enfermeiros receberam, pois o que se evidencia, na maioria dos estudos, é que os cursos de graduação ainda conservam um modelo bancário de ensino, no qual se preserva a transferência do conhecimento de forma fragmentada e verticalizada, percebendo um descompasso entre os currículos das universidades e o atendimento de uma demanda para suprir as reais necessidades sociais. Foi possível evidenciar que ainda existe uma necessidade muito grande de o profissional enfermeiro perceber a importância da prática educativa nas Unidades de Saúde da Família e de se aperfeiçoar os métodos como esta atividade é realizada, para que esta seja uma prática transformadora, ressaltando que o trabalho educativo não é uma tarefa fácil de realizar, principalmente no atual contexto social. Principalmente, é necessário promover uma prática educativa que vise à participação ativa dos usuários, direcionando as atividades de acordo 
com crenças, representações e cultura para que estes se tornem autores do processo educativo, criando vínculos com a equipe de saúde. Sobretudo, percebe-se uma tímida evolução no conceito mais amplo de educação em saúde na perspectiva dos profissionais enfermeiros. Nos estudos analisados, muitos profissionais relatam não realizar esta atividade de forma frequente e nem efetiva, porém reconhecem a importância desta prática e sabem conceituar bem o que é educação em saúde, tanto no modelo tradicional, quanto no modelo emancipatório, sendo esta uma abertura para possíveis transformações positivas. Portanto, acreditando que na área da saúde existe um permanente processo de aprendizagem e que o profissional comprometido irá buscar sempre estratégias para consolidar uma prática transformadora, no qual o usuário se tornará o ator da sua própria estória, poderemos, a partir de então, mudar o atual cenário da saúde no nosso país.

\section{Referências}

ARAÚJO, J. L.; PAZ, E. P. A.; MOREIRA, T. M. M. Hermenêutica e o cuidado de saúde na hipertensão arterial realizado por enfermeiros na Estratégia Saúde da Família. Escola Anna Nery - Impressos, São Paulo, v. 14, n. 3, p. 560-566, 2010. Disponível em: <http://www.scielo.br/scielo.php?script=sci_ arttext\&pid=S0004-27302005000400003 > . Acesso em: 4 nov. 2011.

BACKES V. M. S et al. Competência dos enfermeiros na atuação como educador em saúde. Revista Brasileira de Enfermagem, Brasília, v. 37, n. 3, p. 858-865, 2008. Disponível em: <www. arquivosonline.com.br/pesquisartigos/Pdfs/.../63060004.pdf>. Acesso em: 13 nov. 2011.

BRASIL. Ministério da Saúde. Fundação Nacional de Saúde. Oficinas de educação em saúde e comunicação. Brasília, 2001. Disponível em: <http://dab.saude.gov.br/atencaobasica.php>. Acesso em: 10 nov. 2011.

. Ministério da Saúde. O SUS de A a Z: garantindo saúde nos municípios, Conselho Nacional das Secretarias Municipais de Saúde. Brasília: Editora do Ministério da Saúde, 2009, 480p.

BOEBS, A. E. et al. A interface necessária entre Enfermagem, Educação em Saúde e o conceito de cultura. Texto Contexto Enfermagem, Florianópolis, v. 16, n. 2, p. 307-314, 2007. Disponível em: $<$ http://bvssp.icict.fiocruz.br/lildbi/docsonline/0/1/410-inquerito_comportamentos.pdf $>$. Acesso em: 1으. nov. 2011.

CARRIJO, C. I. S.; PONTES, D. O; BARBOSA, M. A. Reflexão sobre a importância da temática saúde da família no ensino da graduação em Enfermagem. Revista Brasileira de Enfermagem, Brasília, v. 56, n. 2, p. 155-159, 2003. Disponível em: <http://www.ncbi.nlm.nih.gov/pubmed/8258897>. Acesso em: 12 nov. 2011.

CERVO, M. C.; RAMOS, H. Â. C. Conhecimento do enfermeiro sobre atuação em saneamento básico no Programa de Saúde da Família do município de Guarapuava. Revista Espaço para a Saúde, Londrina, v. 7, n. 2, p. 17-23, 2006. Disponível em: <http://www.nature.com/ajh/journal/ v19/n8/pdf/ajh2006149a.pdf>. Acesso em: 14 nov. 2011. 
COSTA, V. Z. et al. Educação permanente no Programa Saúde da Família: um estudo qualitativo. Revista Investigación y Educación en Enfermería, São Paulo, v. 28, n. 3, p. 336-344, 2010. Disponível em: <http://content.nejm.org/cgi/content/abstract/314/19/1226>. Acesso em: 7 nov. 2011.

FERNANDES, M. C. P., BACKES, V. M. S. Educação em saúde: perspectivas de uma equipe da Estratégia Saúde da Família sob a óptica de Paulo Freire. Revista Brasileira de Enfermagem, Brasília, v. 63, n. 4, p. 567-573, 2010. Disponível em: <http://www.scielo.br/scielo.php?pid=S003 471672010000400011\&script=sci_abstract\&tlng=pt>. Acesso em: 5 nov. 2011.

FREIRE P. Pedagogia do oprimido. Rio de Janeiro: Paz e Terra, 1987.

GALVAO, C. M; SAWADA, N.O; TREVIZAN, M.A. Revisão sistemática: recurso que proporciona a incorporação das evidências na prática da enfermagem. Rev. Latino-Am. Enfermagem, Ribeirão Preto, v. 12, n. 3, jun. 2004 .

JESUS, M. C. P. et al. O discurso do enfermeiro sobre a prática educativa no Programa Saúde da Família em Juiz de Fora, Minas Gerais, Brasil. Revista APS, Juiz de Fora, v. 11, n. 1, p. 54-61, jan./ mar. 2008. Disponível em: < http://www.ufjf.br/nates/novo/revista/pdf/v011n1/054-061.pdf >. Acesso em: 12 nov. 2011.

MACHADO, M. F. A. S. et al. Integralidade, formação de saúde, educação em saúde e as propostas do SUS: uma revisão conceitual. Ciência Saúde Coletiva, Fortaleza, v. 12, n. 2, p. 335-342, 2007. Disponível em: <http://www.prosaude.org/publicacoes/diversos/guia_rede_carmen.pdf >. Acesso em: 13 nov. 2010.

OLIVEIRA, R. G., MARCON, S. S. Trabalhar com famílias no Programa de Saúde da Família: a prática do enfermeiro em Maringá, Paraná. Revista Escola de Enfermagem, São Paulo, v. 41, n. 1, p. 65-72, 2007. Disponível em: <www.ee.usp.br/reeusp>. Acesso em: 14 nov. 2011.

PEREIRA, A.L.F. As tendências pedagógicas e a prática educativa nas ciências da saúde. Cad. Saúde Pública, Rio de Janeiro, v. 19, n. 5, out. 2003.

ROCHA, B. S. et al. Enfermeiros coordenadores de equipe do Programa Saúde da Família: perfil profissional. Revista de Enfermagem UERJ, Rio de Janeiro, v. 7, n. 2, p. 229-233, abr./jun. 2009. Disponível em: <http://pesquisa.bvsalud.org/regional/index.php>. Acesso em: 12 nov. 2011.

RODRIGUES, D.; SANTOS, V. E. A educação em saúde na Estratégia Saúde da Família: uma revisão bibliográfica das publicações científicas no Brasil. J Health Sci Inst., São Paulo, v. 28, n. 4, p. 321-324, 2010. Disponível em: < http://www.unip.br/comunicacao/publicacoes/ics/edicoes/ 2010/04_out dez/V.28_n4_2010_p321-324.pdf > Acesso em: 12 nov. 2011.

SANTOS, R. V. P; PENNA C. M. M. A educação em saúde como estratégia para o cuidado à gestante, puérpera e ao recém-nascido. Texto Contexto Enfermagem, Florianópolis, v. 18, n. 4, dez. 2009.

SILVA, M. A. et al. Enfermeiros e grupos em PSF: possibilidade para participação social. Cogitare Enfermagem, Curitiba, v. 11, n. 2, p. 143-149, mai./ago. 2006. Disponível em: <http://ojs.c3sl. ufpr.br/ojs2/index. php/cogitare/article/viewFile/6856/4870>. Acesso em: 14 nov. 2011. 
STEFANELLI, M. C.; CARVALHO E. C. A comunicação nos diferentes contextos da Enfermagem. Barueri (SP): Manole, 2005.

VILLAS BÔAS, L. M. F. M.; ARAÚJO, M. B. S., TIMÓTEO R. P. S. A prática gerencial do enfermeiro no PSF na perspectiva da sua ação pedagógica educativa: uma breve reflexão. Ciência \& Saúde Coletiva, Rio de Janeiro, v. 13, n. 4, p. 1355-1360, 2008. Disponível em: < http://www.scielosp. org/scielo.php?script=sci_arttext\&pid=S1413>. Acesso em: 14 nov. 2011.

Submetido em 23 de maio de 2012.

Aprovado em 23 de agosto de 2012. 